\title{
Isotope-Coded Affinity Tag Protein Analysis
}

National Cancer Institute

\section{Source}

National Cancer Institute. Isotope-Coded Affinity Tag Protein Analysis. NCI Thesaurus. Code C54164.

Recognizing that only a single tryptic peptide is needed to quantify the expression of the corresponding parent protein, the ICAT reagent was designed to affinity isolate and quantify via the use of a stable isotope the relative concentrations of cysteine-containing tryptic peptides obtained from digests of control versus experimental samples. A feature of the ICAT approach is that the in vitro incorporation of a stable isotope into one of the two samples being compared obviates the need to analyze by mass spectrometry the control and experimental samples separately. ICAT data, which is analogous to that obtained via the use of two different fluorescent dyes in DNA microarray analysis of mRNA or DIGE analysis of protein expression, provides the corresponding ratio for the level of expression of the parent protein in the control versus experimental sample. 